\title{
Differences in cNOS/iNOS Activity during Resistance to Trypanosoma cruzi Infection in 5-Lipoxygenase Knockout Mice
}

\author{
Carolina Panis $\mathbb{D}^{1},{ }^{1}$ Vanessa Jacob Victorino, ${ }^{1,2}$ Vera Lúcia Hideko Tatakihara $\mathbb{D}^{2}{ }^{2}$ \\ Rubens Cecchini, ${ }^{3}$ Luiz Vicente Rizzo, ${ }^{4}$ Lucy Megumi Yamauchi ${ }^{(D,}{ }^{5}$ \\ Sueli Fumie Yamada-Ogatta $\mathbb{D}^{5},{ }^{5}$ Marli Cardoso Martins-Pinge, ${ }^{6}$ and Phileno Pinge-Filho $\mathbb{D}^{2}$ \\ ${ }^{1}$ Laboratório de Mediadores Inflamatórios, Universidade Estadual do Oeste do Paraná, Francisco Beltrão, Paraná 85605-010, Brazil \\ ${ }^{2}$ Laboratório de Imunopatologia Experimental, Centro de Ciências Biológicas, Universidade Estadual de Londrina, Londrina, \\ 86051-970 Paraná, Brazil \\ ${ }^{3}$ Laboratório de Patofisiologia e Radicais Livres, Centro de Ciências Biológicas, Universidade Estadual de Londrina, Londrina, \\ Paraná 86051-970, Brazil \\ ${ }^{4}$ Hospital Israelita Albert Einstein, Avenida Albert Einstein 627-701, Subsolo Bloco A., 05651-901 São Paulo, São Paulo, Brazil \\ ${ }^{5}$ Departamento de Microbiologia, Centro de Ciências Biológicas, Universidade Estadual de Londrina, Londrina, \\ Paraná 86051-970, Brazil \\ ${ }^{6}$ Departamento de Ciências Fisiológicas, Centro de Ciências Biológicas, Universidade Estadual de Londrina, Londrina, \\ Paraná 86051-970, Brazil
}

Correspondence should be addressed to Phileno Pinge-Filho; pingefilho@uel.br

Received 18 February 2019; Revised 14 May 2019; Accepted 19 August 2019; Published 24 October 2019

Academic Editor: Alex Kleinjan

Copyright (C) 2019 Carolina Panis et al. This is an open access article distributed under the Creative Commons Attribution License, which permits unrestricted use, distribution, and reproduction in any medium, provided the original work is properly cited.

Infection with the protozoan Trypanosoma cruzi causes Chagas disease and consequently leads to severe inflammatory heart condition; however, the mechanisms driving this inflammatory response have not been completely elucidated. Nitric oxide (NO) is a key mediator of parasite killing in T. cruzi-infected mice, and previous studies have suggested that leukotrienes (LTs) essentially regulate the $\mathrm{NO}$ activity in the heart. We used infected 5-lipoxygenase-deficient mice $\left(5-\mathrm{LO}^{-1-}\right)$ to explore the participation of nitric oxide synthase isoforms, inducible (iNOS) and constitutive (cNOS), in heart injury, cytokine profile, and oxidative stress during the early stage of $T$. cruzi infection. Our evidence suggests that the cNOS of the host is involved in the resistance of $5-\mathrm{LO}^{-1-}$ mice during T. cruzi infection. iNOS inhibition generated a remarkable increase in T. cruzi infection in the blood and heart of mice, whereas cNOS inhibition reduced cardiac parasitism (amastigote nests). Furthermore, this inhibition associates with a higher IFN- $\gamma$ production and lower lipid peroxidation status. These data provide a better understanding about the influence of NO-interfering therapies for the inflammatory response toward T. cruzi infection.

\section{Introduction}

Infection with the hemoflagellate Trypanosoma cruzi causes Chagas disease, essentially leading to morbidity and mortality in Latin America [1-3]. The parasite hampers the host immune response during the acute infection phase, thereby leading to chronic phase with distinct clinical evolution [4]. Early immune response against T. cruzi depends on several signaling factors, such as the production of Th1/Th2 cyto- kines and chemokines [5, 6], eicosanoids [7], and nitric oxide (NO) [8]. NO is crucial in determining the disease outcome against $T$. cruzi infection [9].

In general, $\mathrm{NO}$ is produced mainly from nitric oxide synthase (NOS) activities, presented as inducible (iNOS/NOS2) or constitutive isoforms (cNOS). cNOS are calciumdependent and include neuronal NOS (NOS1) as well as endothelial NOS (NOS3). iNOS is regulated by several factors such as cytokines and microbial-derived products 
yielding abundant NO [10], whereas cNOS is physiologically expressed, generating low levels of NO [11].

Evidence implicates that $\mathrm{NO}$ is pivotal in controlling the parasite burden in experimental T. cruzi infection [12-14], mostly related to the overexpression or enhanced activity of iNOS. In particular, iNOS activation, proinflammatory cytokines, and chemokines produced by cardiomyocytes presumably control the parasite growth and cell influx, thus contributing to the pathogenesis of Chagasic cardiomyopathy as observed in T. cruzi-infected mice [15-17] and rhesus monkeys [14], in addition to Lewis rats infected with T. cruzi (Sylvio X10/7 strain) [18].

NO in the heart is derived from the three NOS isoforms [19]. An advanced study using a mouse model of T. cruzi infection demonstrated that $\mathrm{NO}$ can be regarded as a "double-edged" sword [20]. Despite the importance of NO derived from iNOS to the intracellular killing of parasites, it may lead to myocardial dysfunction [17]. Another study considered iNOS as inessential in controlling T. cruzi infection [21], suggesting the implication of other additional mechanisms in parasite control. In this scenario, other regulatory factors against $T$. cruzi have emerged, such as the eicosanoids $[7,22,23]$.

Leukotrienes (LTs) enhanced the ability of macrophages in eliminating T. cruzi infection [24] and may develop resistance to any infection in a NO-dependent manner [25-28]; in addition, LT deficiency impairs the host immunity against T. cruzi $[26,27]$. These results show 5-lipoxygenase (5-LO) as an important pathway during $\mathrm{NO}$ production due to T. cruzi infection.

In this context, we used 5- $\mathrm{LO}^{-1-}$ deficient mice to investigate the participation of iNOS/cNOS in the heart, oxidative stress, and cytokine profile during the acute infection phase. We found that the cNOS appears to act via mechanisms that favor the parasite survival, whereas the iNOS modulates the infection by maximizing the trypanocidal mechanisms of the host. Thus, this study is the first to demonstrate the differences in the cNOS/iNOS activity considering the resistance toward T. cruzi infection in $5-\mathrm{LO}^{-/-}$mice.

\section{Materials and Methods}

2.1. Animals. Mice (6-10 weeks old, $20-30 \mathrm{~g}$ ) with a targeted disruption of the 5-LO gene $\left(5-\mathrm{LO}^{-/}\right)$[29] and littermate wild-type (WT) controls (129 WT) were purchased from the Jackson Laboratories and were kindly provided by Dr. Fernando Queiroz Cunha (University of Sao Paulo, Ribeirao Preto, Brazil). The animals were housed in a controlled environment and were provided with standard rodent chow and water.

This study was carried out in strict accordance with the principles and guidelines adopted by the Brazilian National Council for the Control of Animal Experimentation (CONCEA), and the technical procedures were approved by the Ethical Committee on Animal Use (CEUA), State University of Londrina (CEUA/UEL: protocol 28568). All surgical procedures were performed under ketamine/xylazine hydrochloride anesthesia, and care was taken to minimize animal suffering.
2.2. Parasite and Infection. T. cruzi (Y strain) [30], belonging to the TcI lineage [31], was kindly provided by Dr. Paulo Araújo, Campinas State University, Brazil, and was maintained by weekly intraperitoneal (i.p.) inoculation of $2 \times 10^{5}$ trypomastigote forms on Swiss mice. For experiments, blood was obtained by cardiac puncture with heparinized syringes and needles. Trypomastigote forms were enumerated in a hematocytometer, and $5 \times 10^{3}$ forms were injected i.p. in mice. Aminoguanidine (AG, selective iNOS inhibitor) [32] and nonspecific NOS inhibitor L-nitroarginine methyl ester (L-NAME) [33] (Sigma-Aldrich, St. Louis, MO, USA) were diluted in sterile phosphate buffer saline (PBS pH 7.2). All solutions were freshly prepared, under sterile conditions.

2.3. Treatment of Animals. The mice received daily i.p. injections of aminoguanidine (AG, $50 \mathrm{mg} / \mathrm{kg} /$ day), L-NAME (LN, $20 \mathrm{mg} / \mathrm{kg} /$ day), or injections containing both inhibitors in the aforementioned concentrations. The first dose was administered at $4 \mathrm{~h}$ after $T$. cruzi infection. The inhibitor dose selected for these experiments was based on the previously published studies demonstrating its efficacy [34-36]. Control experimental groups ( $n=3-5$ animals) received PBS $(0.2 \mathrm{~mL})$ by the same route.

2.4. Parasitemia and Survival Rates. Parasitemia was accessed under standardized conditions, by direct microscopic observation of 50 fields in $5 \mu \mathrm{L}$ of heparinized tail venous blood on alternate days from the 5th day after T. cruzi infection. Data were expressed as number of parasites/per microliter [37]. Survival rate of the infected groups was evaluated for 30 days.

2.5. Blood Collection and Determination of Nitric Oxide (NO) Levels. The control (noninfected) and infected animals (day 12 after infection) were anesthetized, and heparinized blood was collected by cardiac puncture. The plasma was obtained by blood centrifugation at $600 \mathrm{~g}$, for $10 \mathrm{~min}$, at $4{ }^{\circ} \mathrm{C}$ and was stored at $-20^{\circ} \mathrm{C}$ until further analysis. Plasmatic NO was measured as nitrite by reducing nitrate to nitrite with cadmium granules, followed by Griess reaction, as we previously described [26, 38]. Nitrite concentration was quantified using various $\mathrm{NaNO}_{2}$ concentrations as standard, and data were expressed in micromoles.

2.6. Cytokine and Eicosanoid Production. Plasma cytokine levels (IL-2, IL-4, IL-5, IL-6, IL-10, IL-12, IL-13, 1L-17A, IL-23, IFN- $\gamma$, TNF- $\alpha$, and TGF- $\beta 1$ ) were determined using a Multi-Analyte Profiler ELISArray ${ }^{\circledR}$ (Superarray Bioscience Corporation, CAT\#1026 A). Eicosanoid levels were assessed employing the acetylcholinesterase-based assay $\mathrm{PGE}_{2}$ EIA kit and leukotriene $\mathrm{B}_{4}$ EIA kit (Cayman Chemical, CAT\#514531).

2.7. Cardiac Parasitism. The mouse hearts were removed on day 12 i.p., sliced transversally in three sections, and were fixed in $10 \%$ buffered formalin. Paraffin-embedded $5 \mathrm{~mm}$ sections were stained with hematoxylin-eosin stain. Tissue parasitism was evaluated by enumerating the amastigote nest count visualized in three sections per animal [39]. 
2.8. Chemiluminescence Assay. To estimate plasmatic lipoprotein peroxidation, $125 \mu \mathrm{L}$ of plasma was diluted in $865 \mu \mathrm{L}$ phosphate buffer $\left(\mathrm{K}_{2} \mathrm{HPO}_{4} 30 \mathrm{mM}\right.$ in $1.15 \% \mathrm{KCL}$, $\mathrm{pH}=7.4,37^{\circ} \mathrm{C}$ ) and $10 \mu \mathrm{L}$ of tert-butyl hydroperoxide was added. Thereafter, the microtube was quickly put inside a Glomax 20/20 luminometer. Each sample was analyzed for 60 minutes, and the results were achieved from the peaks and the initiation time of the obtained curve [40].

\subsection{Total Antioxidant Capacity of Plasma (TRAP). TRAP} was determined using 2,2' -azobis (ABAP) as a radical generator and luminol to amplify photon detection and light emission using chemiluminescence (CL), according to the method of Repetto et al. Plasma aliquots were diluted at $1: 50$ ratio, and $70 \mu \mathrm{L}$ of these aliquots was added to $830 \mu \mathrm{L}$ of glycine buffer of $0.1 \mathrm{M} \mathrm{pH} 8.6$ and $50 \mu \mathrm{L}$ of luminol solution $(3.98 \mathrm{mg}$ in $250 \mu \mathrm{L}$ of $\mathrm{KOH} 1 \mathrm{M}$ ). About $50 \mu \mathrm{L}$ of $2,2^{\prime}$-azobis (ABAP) solution $(54.24 \mathrm{mg} / \mathrm{mL})$ was added to initiate the reaction. ABAP reacts with lipids present in the plasma, thus forming lipoperoxides that emit photons in the presence of luminol; however, this reaction is inhibited by low molecular antioxidant substances in the plasma $[40,41]$. CL curves were obtained in a GloMax luminometer (TD 20/20, Turner Designs), and the results are expressed in $\mathrm{nM}$ of Trolox.

2.10. Statistical Analysis. Data were processed and analyzed by the analysis of variance (ANOVA) and the Bonferroni posttest or unpaired $t$-tests using GraphPad Prism 6.0 software (La Jolla, CA, USA). Two-tailed values with $95 \%$ confidence intervals were acquired. Data are represented as the error of the mean (SEM). Values of $p<0.05$ were considered as statistically significant.

\section{Results}

3.1. 5-LO Participates in Parasite Burden Control during T. cruzi Infection. Wild-type (129 WT) and 5- $\mathrm{LO}^{-/-}$mice were infected with T. cruzi; parasitemia and survival were monitored according to Panis et al. [26]. Data revealed that the infection peak occurred around the 7th day for both strains (Figure 1(a)). 5- $\mathrm{LO}^{-/-}$presented higher parasitemia levels and lower circulating parasites from the 15th day of infection (Figure 1(a)). Regarding mouse survival rates, we observed that all 129 WT animals infected survived until the 30th day of infection, whereas all the knockout animals died within this period (Figure 1(b)). These data confirmed that the 5-LO signaling pathway is crucial for the animals' survival and resistance to $T$. cruzi infection, as previously described [26]. Moreover, cardiac parasitism (postinfection, 12th day) in knockout mice revealed that the amastigote nests were four times higher than those in 129 WT mice (13.66 \pm 1.56 vs. $3.32 \pm 0.51$, respectively; Figures 1(c), $1(d)$ ), suggesting that the control of multiplication of the parasite in the heart tissue is associated with the 5-LO presence.

3.2. Contrasting Effects of iNOS and cNOS Blockage on Parasite Loading and Relation with Leukotriene Lacking. Considering the confirmation that our disease model repeated the results previously obtained [26] as well as the existing relation between LTs and NO [25], we assessed the role of iNOs and cNOs enzymes during the acute phase of T. cruzi infection. The administration of aminoguanidine (AG) in our data corroborates the findings of previous studies [12], by demonstrating the involvement of iNOS during the acute $T$. cruzi infection. We found a higher number of parasites in the animals treated with AG for both strains (Figures 2(a), 2(d)) -with $50 \%$ of mortality of 129 WT mice until the 28th day after the infection (Figure 3(a)) and 100\% of the knockout group until the 30th day (Figure 3(b)). The assessment of the amastigote nest count in the cardiac tissue (Figure 4) for the group treated with AG revealed higher cardiac parasitism in both strains in a similar manner $(129 \mathrm{WT}=28.33 \pm 4.33$; knockout $=33.01 \pm 10.81)$.

To determine the role of cNOS in acute infection, we subjected the animals to a 30-day L-NAME (LN) injection. We found that the blockage decreased the number of parasites in both strains (Figures 2(b), 2(e)), consequently promoting lower parasite levels in the knockout group (9th day after infection, Figures 2(b), 2(e)). Survival rates in 129 WT animals treated with L-NAME promoted $10 \%$ of mortality after 30 days (Figure $3(\mathrm{a})$ ) and $100 \%$ of mortality for the knockout mice within 22 days (Figure 3(b)). Figures 4(b), 4(c) illustrate the blockade of cNOS providing control of heart parasitism in the knockout animals without changing the nest count in WT animals (Figures 4(a), 4(c)).

In order to assess the simultaneous contribution of iNOS and cNOS in infection control, the mouse groups received concurrent injections of AG and L-NAME. Treatment with AG+L-NAME (AG+LN) enhanced the parasite burden only in the WT group, including a new peak at the 17th day (Figure 2(c)), and reduced the number of blood parasites in the knockout strain until the 11th day as well as increased parasite load from the 13th day (Figure 2(f)). The effect of this simultaneous blockade on the survival rate of WT mice did not cause significant survival reduction (Figure 3(a)), whereas the knockout strain revealed $100 \%$ mortality at the 17th day (Figure 3(b)). Interestingly, no modification on the cardiac parasite load occurred in WT mice with the simultaneous blockage of iNOS and cNOS, regardless of the presence of leukotrienes (Figures 4(a), 4(c)). Notably, the treatment with $\mathrm{AG}+\mathrm{L}-\mathrm{NAME}(\mathrm{AG}+\mathrm{LN})$ provided the knockout animals with heart parasitism control (Figures 4(b), 4(c)).

3.3. NO Production during Acute Infection by T. cruzi Depends on Both iNOS and cNOS, Occurring in the Absence of Leukotrienes. Even though production of iNOS-derived NO during acute T. cruzi infection is considered indispensable for host survival, the role of cNOS-derived NO during infection remains unclear. Considering that LTs and NO are important mediators for host survival against $T$. cruzi $[25,26]$, we investigated the effects of cNOS and iNOS blockage in defining the key source enzyme of NO in the presence and absence of 5-LO.

Our findings $[25,42]$ revealed the occurrence of a basal NO production in control animals (uninfected), regardless of the presence of LTs (Figures 5(a), 5(b)). The infection increased the NO levels in 129 WT animals $(8.44 \pm 1.47$ to 


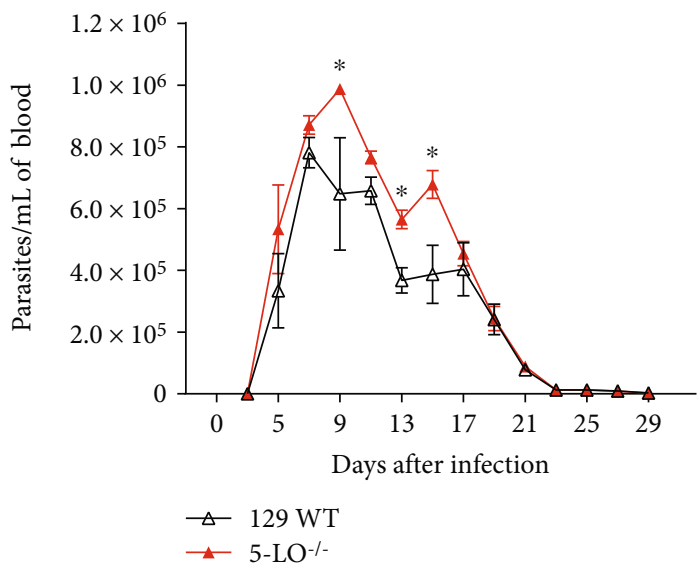

(a)

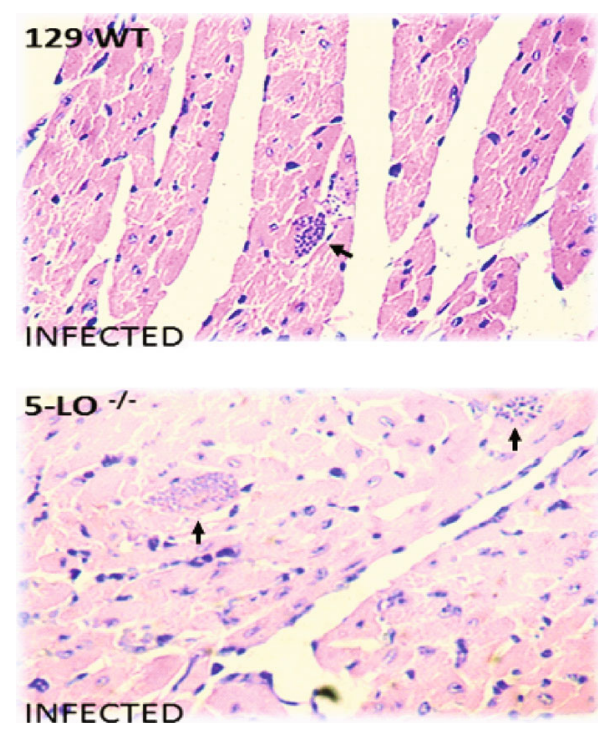

(c)

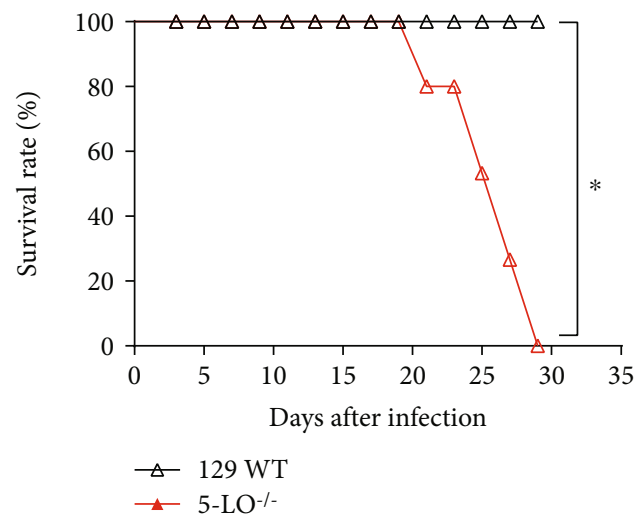

(b)

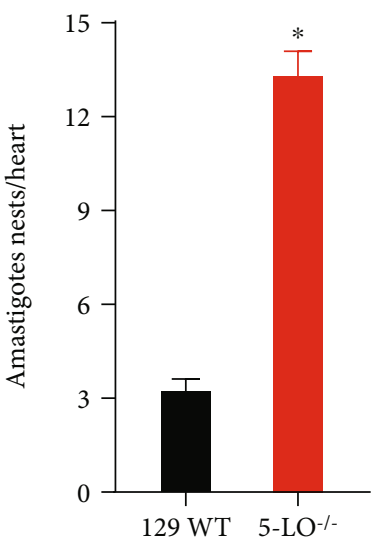

(d)

FIgURE 1: 5-LO pathway signaling is essential for mouse resistance and control of parasitism in T. cruzi infection. (a) Parasitemia and (b) survival rate of $129 \mathrm{WT}$ and $5-\mathrm{LO}^{-/-}$mice infected with $5 \times 10^{3}$ trypomastigote forms of T. cruzi Y strain. (c) Representative images from hematoxylin-eosin staining of heart tissue from $129 \mathrm{WT}$ and $5-\mathrm{LO}^{-/-}$mice 12 days of postinfection. Black arrows indicate amastigote nests. (d) Cardiac parasitism of three heart sections enumerated per mouse. $N=3-5$ animals in each group and values are the mean \pm SEM. ${ }^{*} p<0.001$.

$59.781 \pm 13.69$, Figure $5(\mathrm{a}))$ as well as in knockout mice (from $8.24 \pm 1.39$ to $82.04 \pm 8.45$, Figure 5(b)) indicating a higher NO production during infection upon the absence of LTs.

Treatment with AG generated lower NO levels in infected 129 WT mice (from $59.78 \pm 13.69$ to $16.96 \pm 6.54$, Figure 5(a)) and infected 5- $\mathrm{LO}^{-1-}$ mice (from $82.04 \pm 8.45$ to 39.56 (Figure 5(b)). cNOS inhibition led to a significant decrease in NO production only in the infected knockout animals ( $82.04 \pm 8.45$ to $38.79 \pm 16.9$; Figure $5(\mathrm{~b}))$, whereas the coinhibition of iNOS and cNOS caused a significant decrease only in the $5-\mathrm{LO}^{-1-}$ group (from $82.04 \pm 8.45$ to $35.17 \pm 14$; Figure 5(b)).

3.4. Cytokine Production Is Influenced by Leukotrienes and Altered by NOS Blockage. In order to elucidate whether the production of cytokines is influenced by leukotrienes and the blockage of iNOS and cNOs during T. cruzi infection, we established the levels of Th1/Th2 systemic cytokines in both mouse strains (Figure 6). Basal levels found in the control groups (uninfected) reveal that the knockout mice displayed lower levels of IL-6 than the WT (Figure 6(d)), in addition to low levels of IL-13, IL-17a, IL-23, and TGF- $\beta 1$ (Figures 6(a), 6(d)). Notably, we observed an increment in IL-6 production during acute T. cruzi infection for both 129 WT and knockout mice (Figures 6(a), 6(d)).

iNOS blockage generated higher IL-10, IL-13, IFN- $\gamma$, TNF- $\alpha$, and TGF- $\beta 1$ in WT mice along with a lower IL-6 reduction in relation to untreated $T$. cruzi animals (Figure 6(a)). Knockout animals revealed lower IL-6 levels during aminoguanidine $(\mathrm{AG})$ treatment in relation to the infected untreated mice (Figure 6(d)). cNOS inhibition 


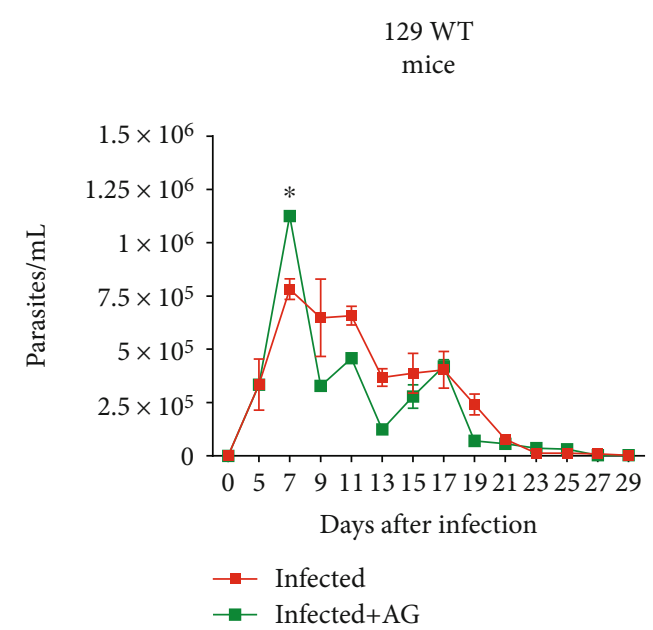

(a)

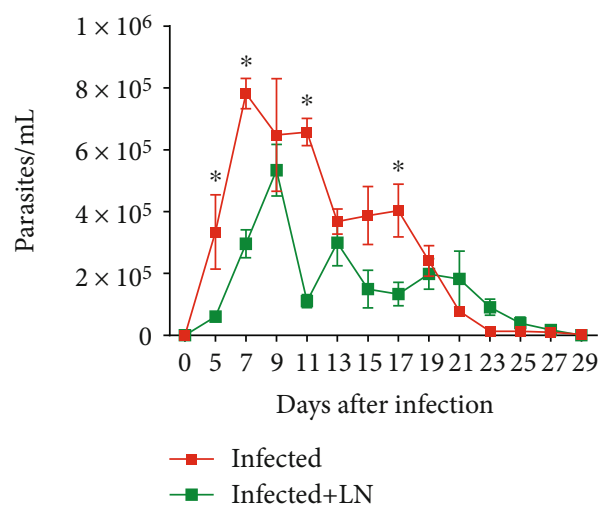

(b)

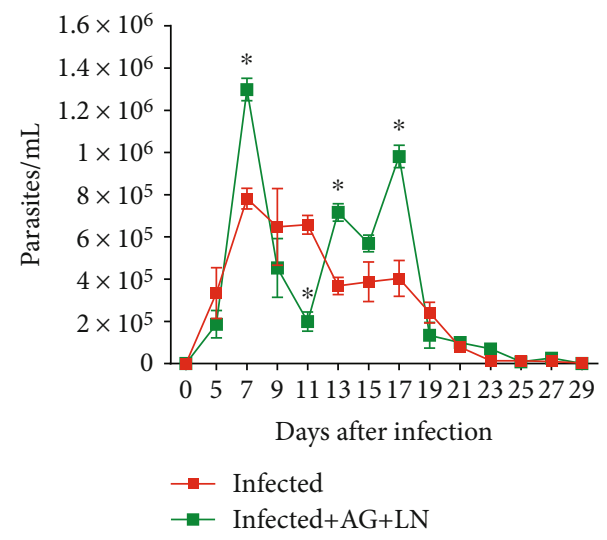

(c)

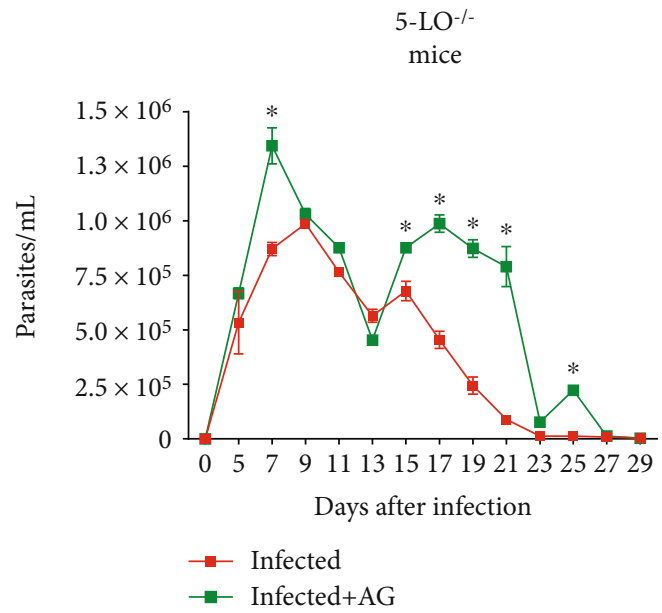

(d)

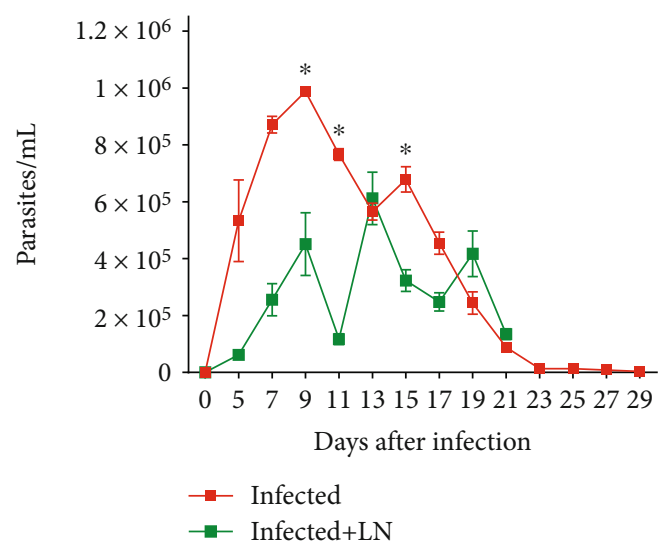

(e)

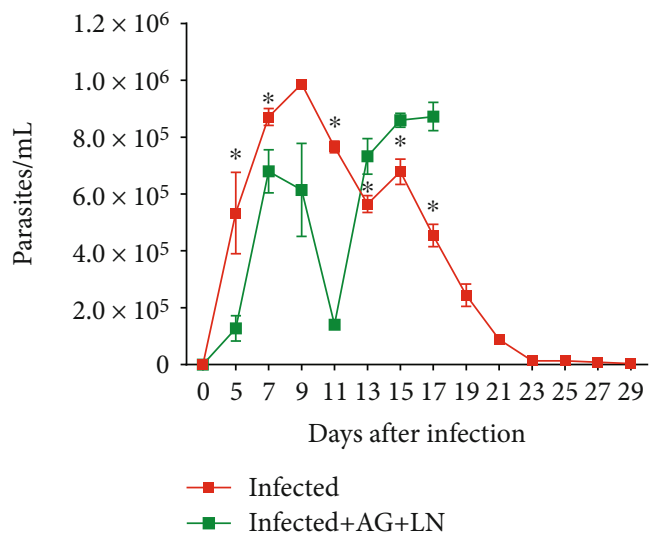

(f)

FIgURE 2: Differences in cNOS/iNOs activity considering the resistance to T. cruzi infection. (a-f) Parasitemia of 129 WT and 5-LO ${ }^{-/-}$mice infected with $5 \times 10^{3}$ trypomastigote forms of T. cruzi Y strain. Mice were treated $4 \mathrm{~h}$ before infection and were administered i.p. daily for 30 days, employing inhibitors dose as follows: aminoguanidine (AG, iNOS inhibitor, $50 \mathrm{mg} / \mathrm{kg} / \mathrm{day}$ ), N $\omega$-nitro-L-arginine methyl ester hydrochloride (L-NAME, $20 \mathrm{mg} / \mathrm{kg} /$ day), or both. Control experimental groups received PBS $(0.2 \mathrm{~mL} / \mathrm{mouse}) . \mathrm{N}=5$ animals in each group and values are the mean \pm SEM. ${ }^{*} p<0.001$.

promoted an increment in IL-10 production in 129 WT and $5-\mathrm{LO}^{-/-}$mice compared with the untreated mice (Figures 6(b), 6(e)) and had higher IFN- $\gamma$ in $5-\mathrm{LO}^{-/-}$mice (Figure 6(e)). Coinhibition increased the levels of IFN- $\gamma$,
TNF- $\alpha$, and TGF- $\beta 1$ in the 129 WT group (Figure 6(c)), whereas the knockout group revealed lower IL- 6 in addition to augment the IL-10, IL-12, IL-13, IL-17a, IL-23, IFN- $\gamma$, TNF- $\alpha$, and TGF- $\beta 1$ levels (Figure 6(f)). 


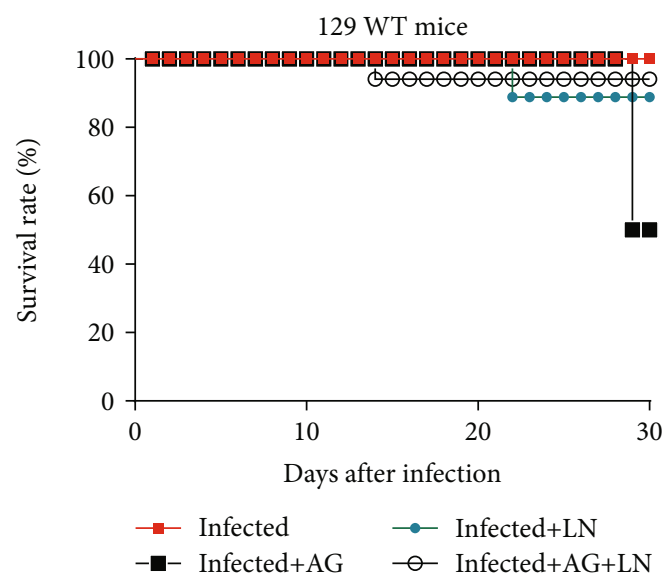

(a)

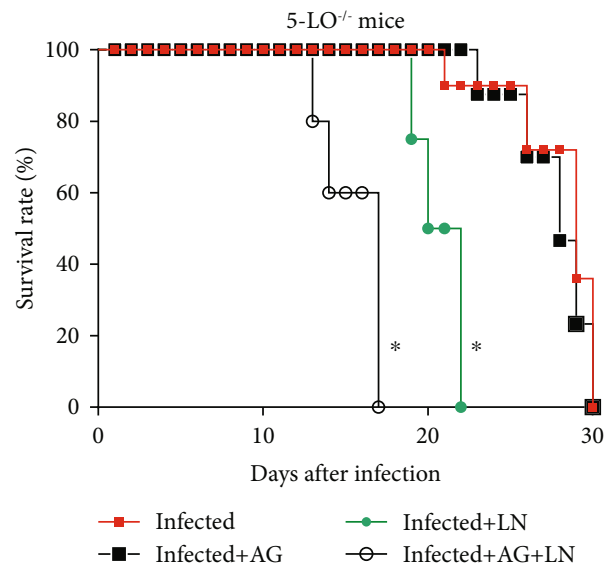

(b)

FIgURE 3: Survival rate of T. cruzi-infected mice treated with iNOS/cNOS blockers. (a) 129 WT mice and (b) 5-LO ${ }^{-/-}$mice infected with $5 \times 10^{3}$ trypomastigote forms of T. cruzi Y strain. Mice were treated $4 \mathrm{~h}$ before infection and were administered i.p. daily for 30 days, employing inhibitors dose as follows: aminoguanidine (AG, iNOS inhibitor; $50 \mathrm{mg} / \mathrm{kg} / \mathrm{day}$ ), N $\omega$-nitro-L-arginine methyl ester hydrochloride (L-NAME [57], $20 \mathrm{mg} / \mathrm{kg} /$ day), or both. Control experimental groups received PBS $(0.2 \mathrm{~mL} / \mathrm{mouse}) . N=5$ animals in each group and values are the mean \pm SEM. ${ }^{*} p<0.001$.

3.5. NOS Blockage Alters Oxidative Stress Levels during T. cruzi Infection. Considering that lipoxygenase pathway is crucial in erythrocyte oxidative stress through NO in Chagas' disease [27], we analyzed the effect of iNOS and cNOs blockage on the antioxidant/oxidative status during early T. cruzi infection.

According to Figure 7(a), the plasma of knockout mice presented higher basal levels of lipoperoxides than that of the 129 WT animals (Figure 7(a)). The infection led to increased levels of lipoperoxidation in both mouse strains, whereas $5-\mathrm{LO}^{-1-}$ revealed higher levels compared to the 129 WT mice (Figure 7(a)). The AG administration generated higher stress levels in 129 WT infected mice as well as lower lipoperoxidation in infected knockout mice (Figure 7(b)). Additionally, L-NAME (LN) and the cotreatment with AG and L-NAME (LN) reduced lipoperoxidation in both mouse strains (Figures $7(\mathrm{c}), 7(\mathrm{~d})$ ). TRAP levels did not reveal significant alterations (Figures 8(a), 8(b)).

3.6. Eicosanoid Balance during T. cruzi Infection and NOS Inhibition. We did not detect the production of $\mathrm{LTB}_{4}$ in the $5-\mathrm{LO}^{-/-}$plasma of the mice used in the study, regardless of the infection or treatment using NOS inhibitors (data not shown). Interestingly, the $\mathrm{PGE}_{2}$ amount released from 5$\mathrm{LO}^{-1-}$ before or after T. cruzi infection was greater than that released from the wild-type plasma (Figure 9(a)). The treatment using NOS blockers generated lower $\mathrm{PGE}_{2}$ levels in the plasma only for the $5-\mathrm{LO}^{-1-}$ infected mice (Figure 9(b)).

\section{Discussion}

Higher levels of iNOS expression have been associated with Chagas disease [16] since nitric oxide (NO) is toxic to T. cruzi $[12,43]$; however, data from iNOS-deficient mice are contro- versial in the context of $T$. cruzi infection as the iNOSdeficient mice are resistant to T. cruzi [21]. Our study investigated the involvement of iNOS/cNOS during the acute T. cruzi infection by using $5-\mathrm{LO}^{-/-}$mice as an infection model.

Previous studies have reported that leukotrienes (LTs) are essential in NO production during parasitic infections, particularly those occurring due to from iNOS activity [25, 43-45]. Accordingly, infected 5- $\mathrm{LO}^{-/-}$mice displayed lower $\mathrm{NO}$ production and iNOS protein expression in the heart compared to the WT infected mice, thus revealing that LTs may be required for optimum NO-dependent restriction of tissue parasitism [24]. In addition, different results for NO and cytokine productions occurred during the acute phase of T. cruzi infection in 5- $\mathrm{LO}^{-1-}$ mice, which has been related to resistance $[28,46]$ or susceptibility [26] presumably due to different trypomastigotes used to infect the experimental groups of mice.

Talvani et al. investigated the ability of $\mathrm{LTB}_{4}$ to induce NO production by macrophages infected with $T$. cruzi in vitro and whether NO mediated LTB4-induced parasite killing [25]. The authors demonstrated that the activation of macrophages with $\mathrm{LTB}_{4}$ induced a concentration- and time-dependent increase in NO production by $T$. cruziinfected macrophages. Blockade of NO production with an iNOS inhibitor reduced the microbicidal activity of $\mathrm{LTB}_{4}$. In general, these results provide strong experimental evidence suggesting that the activation of T. cruzi-infected macrophages with $\mathrm{LTB}_{4}$ induces the production of TNF- $\alpha$, which drives NO release. The NO produced was then responsible for parasite replication control [25].

We decided to apply an interventional strategy (5-LO gene deletion) [29] targeting both cysteinyl-LTs and LTB4. In particular, $\mathrm{LTB}_{4}$ production was not detected from the plasma of $5-\mathrm{LO}^{-1-}$ mice used regardless of infection or 


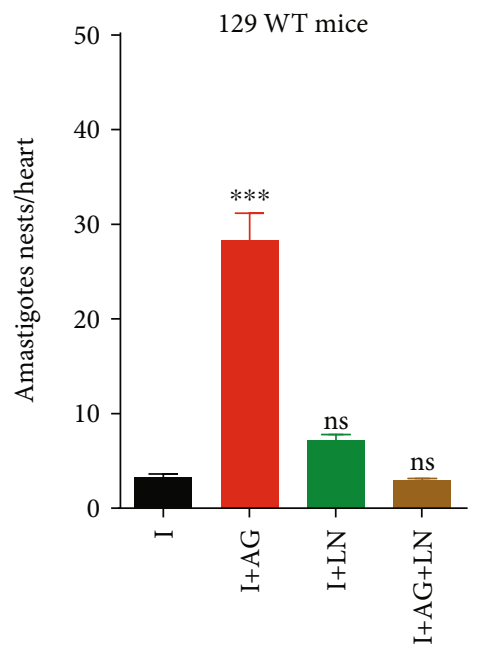

(a)

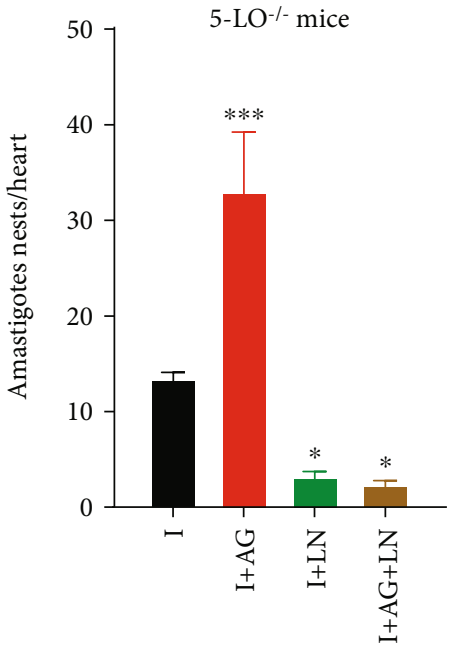

(b)

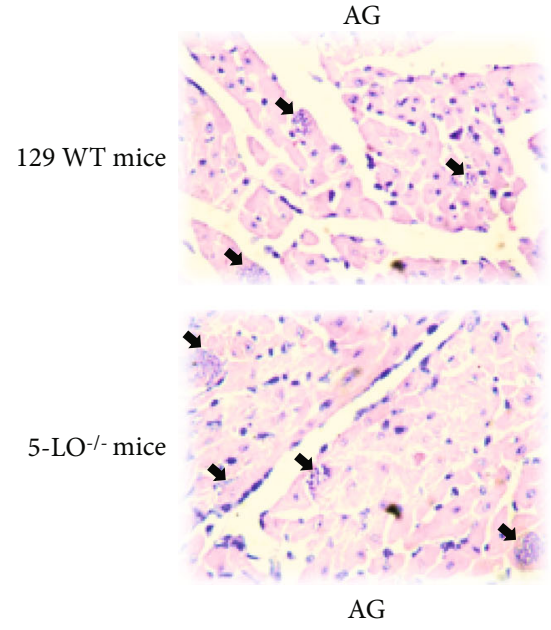

$\mathrm{AG}$

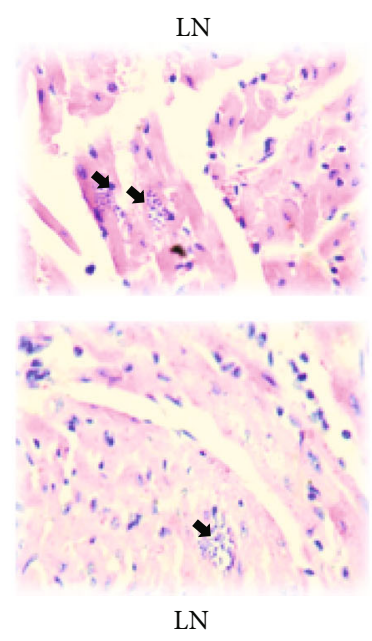

(c)

Figure 4: Cardiac parasitism. Number of amastigote nests in (a) wild-type (129 WT mice) and (b) 5 - $\mathrm{LO}^{-1-}$ mice infected with $5 \times 10^{3}$ trypomastigote forms of T. cruzi (day 12 of postinfection). (c) Photomicrographs of cardiac sections stained with hematoxylin-eosin. AG: infected mice treated with aminoguanidine $(50 \mathrm{mg} / \mathrm{kg} / \mathrm{day}$ i.p.); LN: infected mice treated with L-NAME (20 mg/kg/day i.p.); AG+LN: infected mice treated with aminoguanidine ( $50 \mathrm{mg} / \mathrm{kg} / \mathrm{day}$ i.p. plus L-NAME $20 \mathrm{mg} / \mathrm{kg} /$ day). $n=3$ animals in each group and values are the mean \pm SEM for three independent experiments, ${ }^{*} p<0.001$. ns: not significant, $p>0.05$ compared with control group (untreated and infected).

treatment with NOS inhibitors. Unexpectedly, we present that the induction of elevated $\mathrm{NO}$ production in the plasma during $T$. cruzi acute infection occurred in the absence of 5-LO activity, suggesting that LT-independent mechanisms may be operative. The possible involvement of cNOS-derived NO against T. cruzi and its relationship with eicosanoids is yet to be investigated.

Our results revealed that iNOS blockage increased the circulating parasite load and reduced the overall survival in both mouse lineages in relation to the respective untreated infected groups; however, such effect was more prominent in the knockout group suggesting that iNOS is necessary to control the parasite load in the absence of 5-LO. Conversely, cNOS blockage significantly reduced the overall survival of $5-\mathrm{LO}^{-1-}$ animals indicating that cNOS may modulate the parasite survival positively during acute T. cruzi infection.
During the T. cruzi infection, cardiac cells are extensively infected, and the amastigotes form several parasite nests. Cardiomyocytes are the cells that are able to express iNOS during T. cruzi infection and minimize its multiplication via this pivotal route $[18,47]$ presumably contributing to NO production in macrophages.

Accordingly, we demonstrated that $5-\mathrm{LO}^{-1-}$ mice led to a fourfold increase process in amastigote nests in relation to the wild-type mice and revealed that iNOS is relevant for both the experimental groups used. Chandrasekar et al. [18] reported enhanced cardiac cNOS expression at the 3rd day after T. cruzi infection in rats, without any association with systemic NO production. Our results suggest the essential activation of the cNOS pathway in the absence of 5-LO metabolites that benefit parasite multiplication since the blockage of this system causes extremely low parasite loads compared to the untreated infected mice. 


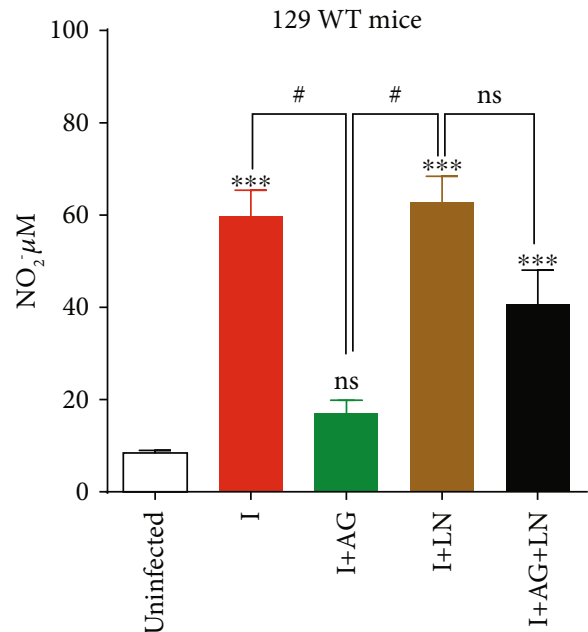

(a)

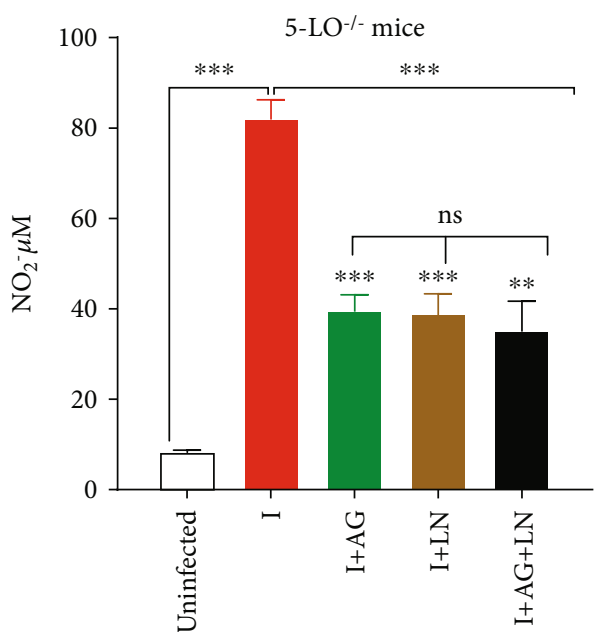

(b)

Figure 5: Nitric oxide (NO) production. (a) Wild-type (129 WT mice) and (b) 5-LO ${ }^{-/-}$mice infected with $5 \times 10^{3}$ trypomastigote forms of T. cruzi Y strain and treated or untreated with NOS inhibitors. NO was determined by measuring the nitrite levels in plasma employing the cadmium-copper system followed by the Griess reaction. $N=5$ animals in each group and values are the mean \pm SEM for three independent experiments. ${ }^{*} p<0.001$. ${ }^{\#} p<0.001$, ns: not significant, $p>0.05$ compared with uninfected group or between groups.

Measurement of plasma NO clearly presented the distinct involvement of NOS isoforms in acute infection: iNOS, but not cNOS, was essential for infected mice from the wild-type group since cNOS blockage revealed no alteration in the NO levels. In contrast, we found that cNOS blockage reduced the NO to the same levels of iNOS inhibition in the knockout group, which indicates that in the absence of LTs, cNOS-derivated NO must be an additional defense mechanism against T. cruzi.

Although 5-LO deficiency is a presumable limiting factor for the inflammatory response generation in the knockout animals, the production of proinflammatory cytokines and NO during T. cruzi infection has been described for this experimental model [26].

We demonstrated that the two strains of mice examined could respond to the parasite presence by producing cytokines despite distinct profiles. Knockout uninfected animals had lower basal levels of IL-6 compared to the wild-type mice, which may be related to their disability in the production of LTs, and consequently, low capacity to generate a satisfactory inflammatory response by $\mathrm{T}$ lymphocytes [48].

An increase in the proinflammatory cytokine IL-6 occurred during the acute infection phase with T. cruzi for both the wild-type and knockout mice. Low levels of IL-13, IL-17a, IL-23, and TGF- $\beta 1$ were also found in these animals, suggesting that this mechanism can be a limiting factor to generate inflammatory response in the absence of leukotrienes. The higher levels of IL- 6 verified may be associated with the role of this cytokine in the acute inflammatory response to infection through the activation and differentiation of $\mathrm{T}$ lymphocytes, stimulation of hepatic production of acute phase proteins, and antibody production by $\mathrm{B}$ lymphocytes [49].

We further observed that iNOS blockage increased the IL-10, IL-13, IFN- $\gamma$, TNF- $\alpha$, and TGF- $\beta 1$ in the WT mice along with IL- 6 reduction compared to the untreated T. cruzi-infected mice. The cytokine profile observed in wildtype animals during iNOS blockage suggests a shift in the pattern of cellular response with the production of Th2 pattern cytokines. IFN- $\gamma$ and TNF- $\alpha$ mediators are essential in NO production and antiparasitic responses [43]. Therefore, elevated levels may reflect a higher production of these cytokines to stimulate macrophages in order to increase the NO levels observed during iNOS blockade. Inhibition of cNOS during infection caused higher IL-10 production in the wild-type group and increased IFN- $\gamma$ levels in knockout mice suggesting a change in cytokine profile upon cNOS absence for both mouse groups. Such alteration in the cytokine profiles did not modify the remaining parameters assessed during the course of infection in the WT group (cardiac parasitism, survival, parasitemia, and NO levels) indicating that cNOS does not participate in the regulatory mechanisms of protecting these animals in response to T. cruzi acute infection.

The involvement of cNOS during acute infection became quite pronounced in the knockout animals since its blockage induced higher plasma levels of IFN- $\gamma$, described as the main inducer of NO production [50]; however, such IFN- $\gamma$ increase was not sufficient to maintain or increase the levels of NO produced by iNOS in response to infection during cNOS blockade in our model.

Blocking of NO production by cNOS and iNOS simultaneously generated higher levels of IFN- $\gamma$, TNF- $\alpha$, and TGF- $\beta$ in both strains demonstrating that these enzymes participate in the systemic processes regulating the patterns of cytokines produced in response to T. cruzi.

Peripheral polymorphonuclear cells are presumably the cellular types involved in NO production in the plasma. These results suggest that the endogenous production of lipid mediators and action on their respective receptors could be 


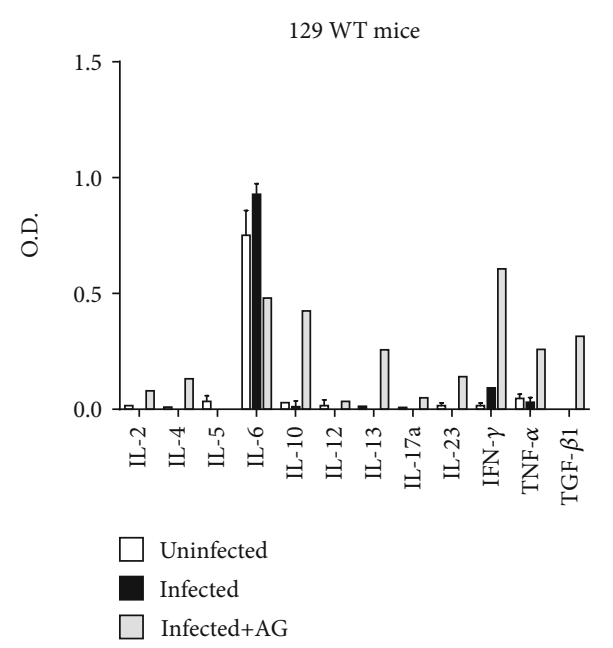

(a)

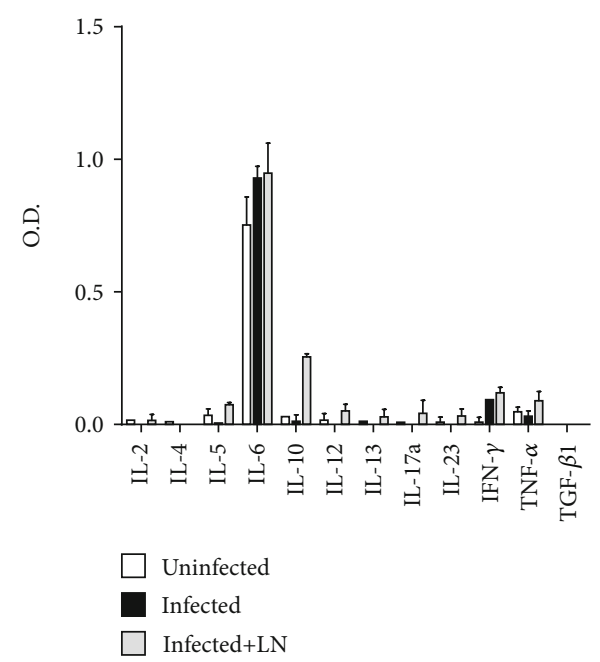

(b)

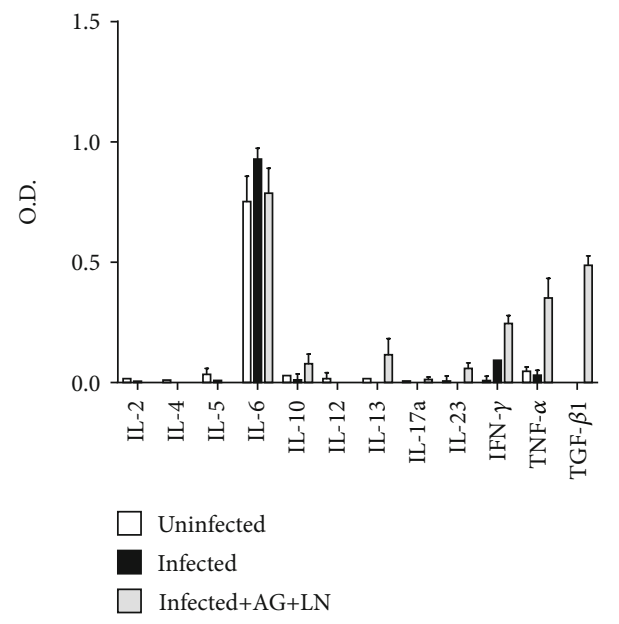

(c)

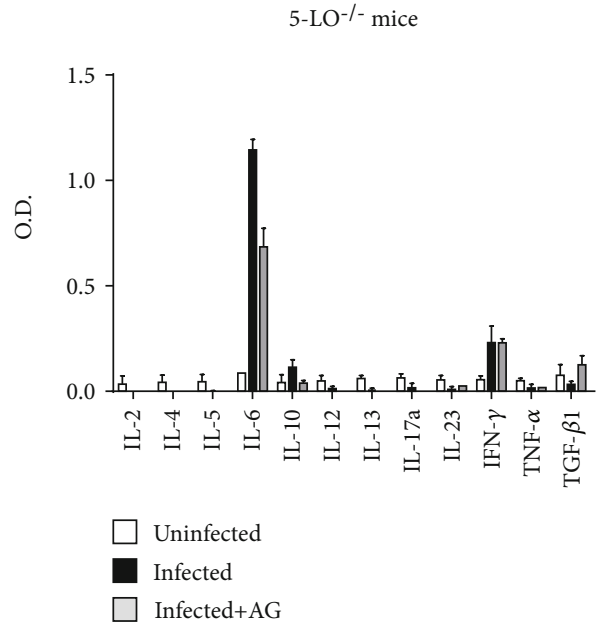

(d)

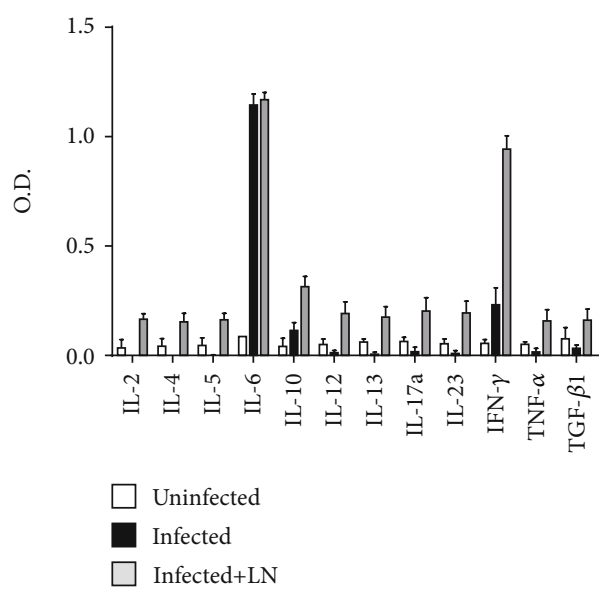

(e)

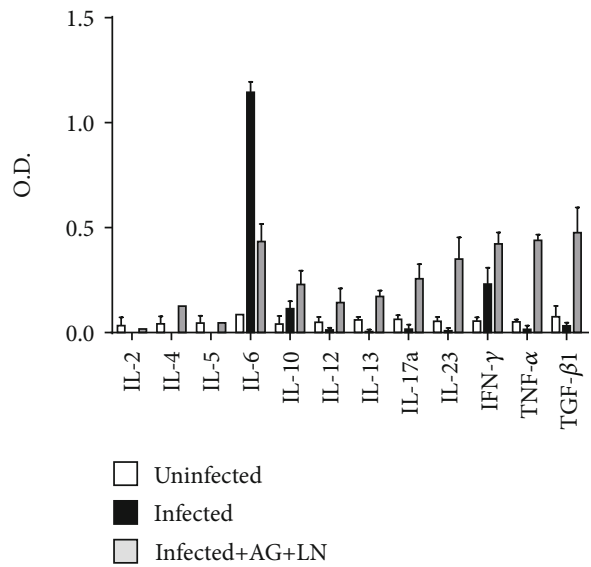

(f)

Figure 6: Plasma levels of cytokines after treatment with NOS inhibitors. Three independent samples, each for 129 WT mice (a-c) and $5-\mathrm{LO}^{-/-}$mice $(\mathrm{d}-\mathrm{f})$, were used. AG: infected mice treated with aminoguanidine $(50 \mathrm{mg} / \mathrm{kg} / \mathrm{day}$ i.p.); LN: infected mice treated with L-NAME (LN; $20 \mathrm{mg} / \mathrm{kg} /$ day i.p.); AG+LN: infected mice treated with aminoguanidine (50 mg/kg/day i.p. plus L-NAME $20 \mathrm{mg} / \mathrm{kg} / \mathrm{day}) . \mathrm{Mean} \mathrm{OD}$ values of Multi-Analyte ELISArray results for indicated cytokines are presented; OD $>1.0$ is indicated as 1.0. Data are representative of two independent experiments. $N=5$ animals in each group and values are the mean \pm SEM. ${ }^{*} p<0.001$. 


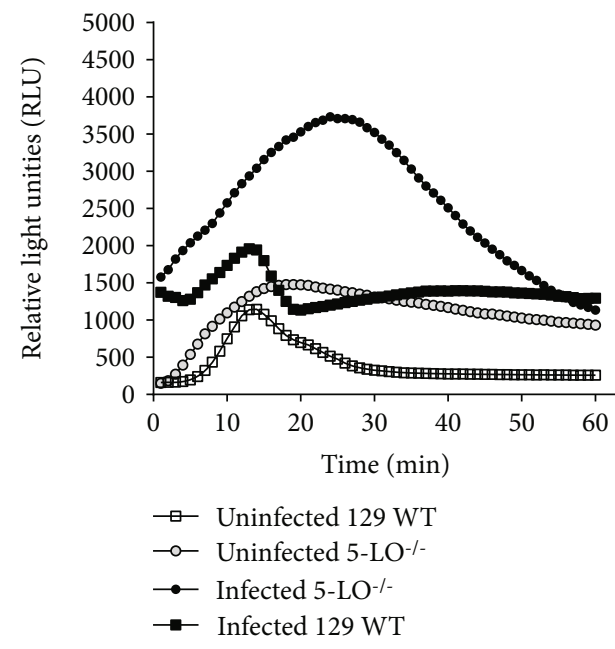

(a)

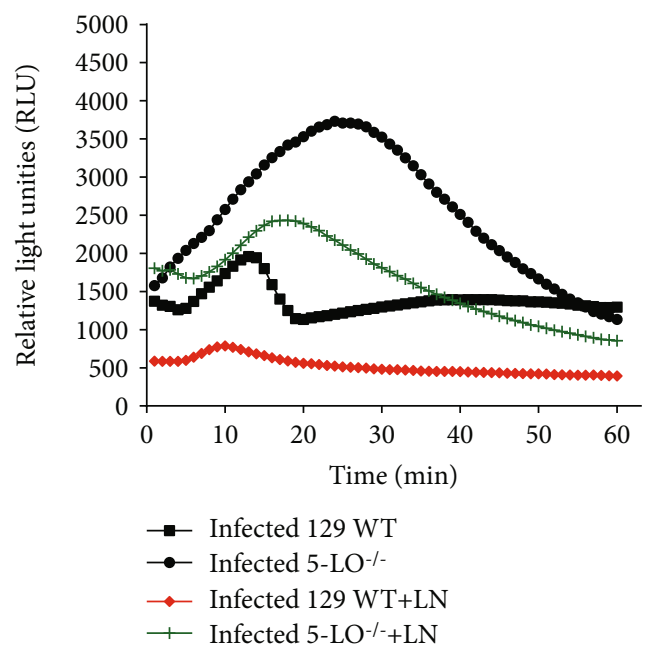

(c)

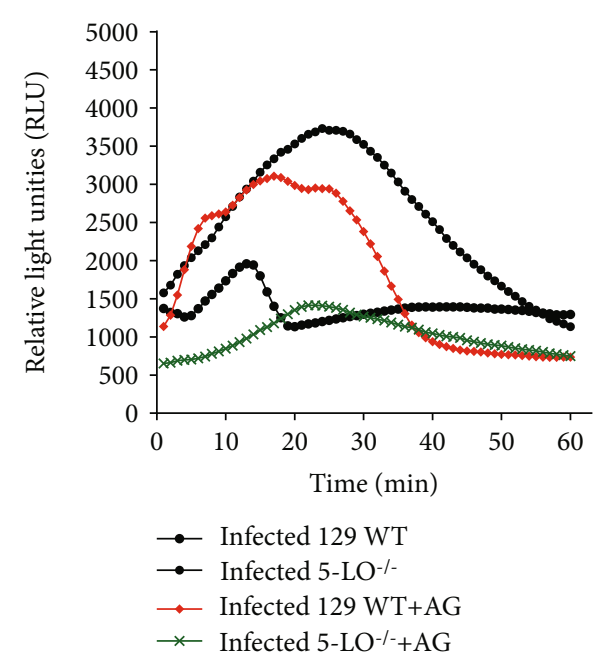

(b)

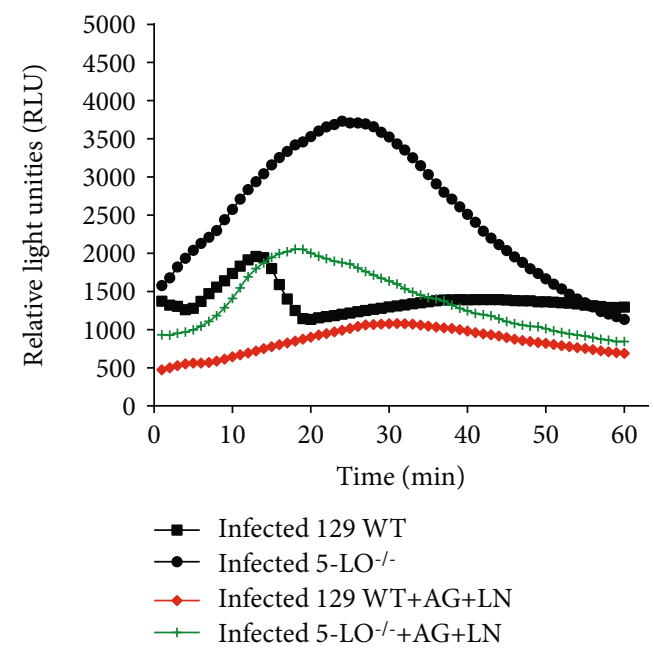

(d)

Figure 7: Oxidative stress profile evaluated by tert-butyl hydroperoxide-initiated chemiluminescence on day 12 after T. cruzi infection. (a-d) Mice were infected with $5 \times 10^{3}$ trypomastigote forms of T. cruzi (Y strain) and were treated or untreated with NOS inhibitors. (a) Uninfected mice and untreated T. cruzi-infected mice were used as controls. (b) AG: infected mice treated with aminoguanidine (50 mg/kg/day i.p.); (c) LN: infected mice treated with L-NAME (LN; $20 \mathrm{mg} / \mathrm{kg} /$ day i.p.); (d) AG+LN: infected mice treated with aminoguanidine $(50 \mathrm{mg} / \mathrm{kg} /$ day i.p. plus L-NAME $20 \mathrm{mg} / \mathrm{kg} /$ day). $N=5$ animals in each group. Values represent the mean \pm SEM and are representative of two independent experiments ${ }^{*} p<0.001$.

responsible for part of the IFN- $\gamma$ ability to induce $\mathrm{NO}$ and TNF- $\alpha$ production in infected mice. In particular, an increment of IFN- $\gamma$ occurred during the acute infection phase with T. cruzi infection in the knockout mice used (particularly those treated with NO inhibitors).

Despite the record of an alteration in the in vitro production of multiple cytokines by 5 -LO-derived leukotrienes $[51,52]$, the functional significance of these changes in vivo during $T$. cruzi infection remains unclear. Immune and inflammatory responses are not only mediated by cytokines produced by lymphocytes and other cell types but also by arachidonic acid metabolites (PGs and LTs). These cytokines and lipid mediators form a complex network with everyone and can regulate each other's production. Our findings raise the question that one mechanism for the NO production from plasma of infected 5- $\mathrm{LO}^{-/-}$ mice can be the increased production of IFN $-\gamma$. However, the mediators of this response still need to be identified.

Considering this complex net of cytokines and the influence of NOS system, evidence indicates that NO can modulate the biological levels of arachidonate-derived cell signaling molecules leading to either the stimulation or inhibition of its activity depending on the interaction with specific NO metabolites [53, 54]. COX metabolites are described as important mechanisms of host defenses against T. cruzi $[55,56]$.

$\mathrm{PGE}_{2}$ has the capacity of NO upregulation [57]; however, in our model, the mice did not reveal this correlation. Knockout mice displayed higher basal levels of prostaglandins in relation to the WT mice suggesting that lack of 5-LO could 


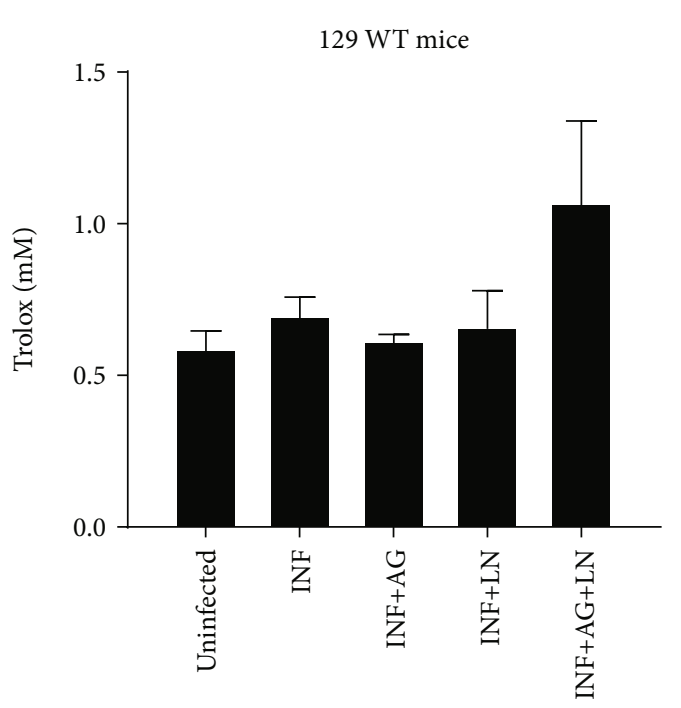

(a)

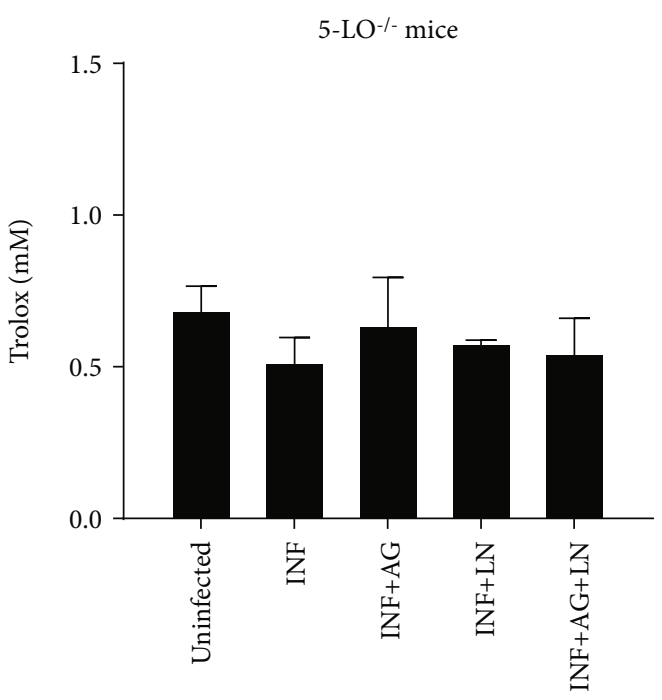

(b)

Figure 8: Plasmatic antioxidant profile. (a) Wild-type (129 WT mice) and (b) 5 -LO $\mathrm{LO}^{-/-}$mice. Mice were infected with $5 \times 10^{3}$ trypomastigote forms of T. cruzi (Y strain) and were treated or untreated with NOS inhibitors. AG: infected mice treated with aminoguanidine (50 mg/kg/day i.p.); LN: infected mice treated with L-NAME (LN; $20 \mathrm{mg} / \mathrm{kg} /$ day i.p.); AG+LN: infected mice treated with aminoguanidine (50 mg/kg/day i.p. plus L-NAME $20 \mathrm{mg} / \mathrm{kg} /$ day). Uninfected mice were used as controls. $N=5$ animals in each group. Values represent the mean \pm SEM and are representative of two independent experiments ${ }^{*} p<0.001$.

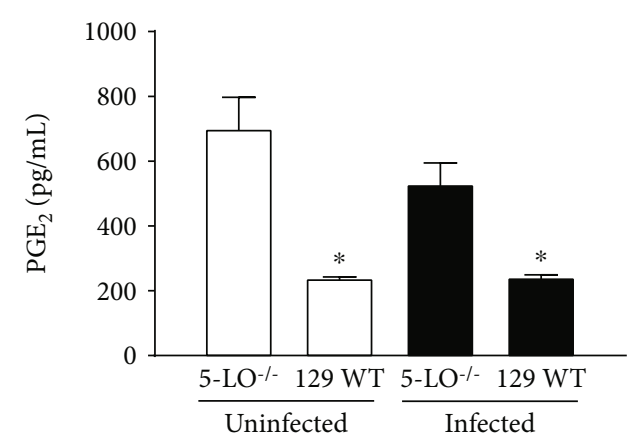

(a)

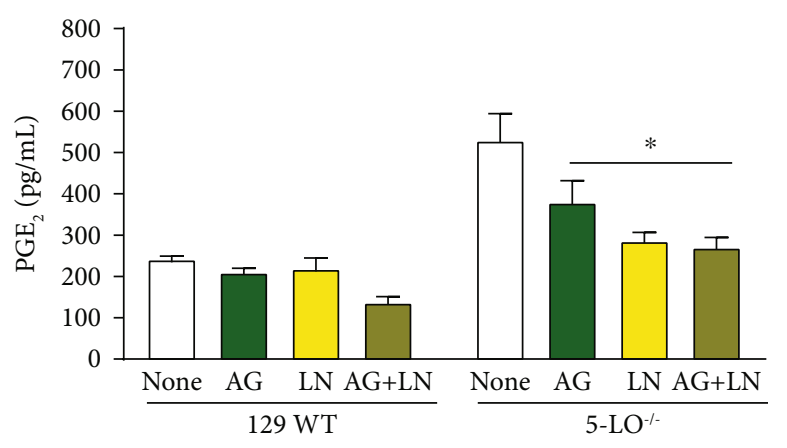

(b)

Figure 9: Plasma levels of $\mathrm{PGE}_{2}$. (a) Wild-type (129 WT mice) and 5-LO ${ }^{-/-}$mice uninfected and infected and (b) treated or untreated with NOS inhibitors. AG: infected mice treated with aminoguanidine $(50 \mathrm{mg} / \mathrm{kg} / \mathrm{day}$ i.p.); LN: infected mice treated with L-NAME (LN; $20 \mathrm{mg} / \mathrm{kg} /$ day i.p.); AG+LN: infected mice treated with aminoguanidine (50 mg/kg/day i.p. plus L-NAME $20 \mathrm{mg} / \mathrm{kg} / \mathrm{day}) . \mathrm{Mice}$ were infected with $5 \times 10^{3}$ trypomastigote forms of $T$. cruzi (Y strain). $N=3$ animals in each group and values are the mean \pm SEM. ${ }^{*} p<0.001$ compared with the control group.

deviate the arachidonic acid metabolism to a further production of prostaglandins by cyclooxygenases. Infection did not alter the prostaglandin production in both groups, whereas the aminoguanidine and L-NAME treatments, associated or unassociated, led to a reduction in $\mathrm{PGE}_{2}$ levels from the $5-\mathrm{LO}^{-1-}$ group.

In addition to NO, T. cruzi infection leads to the production of oxygen-reactive species induced by proinflammatory cytokines, as TNF- $\alpha$, through mitochondrial free radical generation [58]. Additionally, $\mathrm{NO}$ is capable of reacting via multiple pathways to modulate lipid oxidation as well as the production of inflammatory and vasoactive eicosanoids by prostaglandin endoperoxide synthase and lipoxygenase [59].
Therefore, our results revealed that plasma lipoperoxidation is augmented during T. cruzi infection in both groups. iNOS and cNOS blockage presented distinct results: in the WT group, aminoguanidine treatment led to higher levels, whereas L-NAME reduced the oxidative stress to control levels. Moreover, in knockout mice, iNOS blockage reduced this event to the control levels, whereas cNOS presented a partial decrease in lipoperoxidation in relation to the untreated infected animals.

\section{Conclusion}

In summary, our study found that the NOS isoforms studied revealed opposite effects in response to acute infection with 
T. cruzi. cNOS appears to act via mechanisms that favor parasite survival, whereas iNOS modulates the infection by maximizing the host's trypanocidal mechanisms. Another important point is the regulation exerted by 5 -LO metabolites over NOS activities and cytokine profile. It is important to conduct further studies in order to clarify the molecular mechanisms regulating host responses and allow an improved understanding of the NOS role in the complex net formed by cytokines and stress mediators during T. cruzi infection.

\section{Abbreviations}

5-LO: 5-Lipoxygenase

5- $\mathrm{LO}^{-/-}$mice: 5-Lipoxygenase knockout mice

WT: Wild type

iNOS/ $\mathrm{NOS}_{2}$ : Inducible nitric oxide synthase

cNOS: $\quad$ Constitutive nitric oxide synthase

NO: $\quad$ Nitric oxide

AG: Aminoguanidine

LN: $\quad$ L-NAME

LTs: $\quad$ Leukotrienes.

\section{Data Availability}

The data used to support the findings of this study are available from the corresponding author upon request.

\section{Conflicts of Interest}

The authors declare that there is no conflict of interest that would prejudice the impartiality of this scientific work.

\section{Acknowledgments}

The authors are grateful to Jesus Vargas for excellent technical assistance. CPL was supported by the Coordenação de Aperfeiçoamento de Pessoal de Nível Superior (CAPES). LVR, SFY-O, LMY, MM-P, and PP-F are recipients of personal fellowships from $\mathrm{CNPq}$.

\section{References}

[1] C. Chagas, "Nova tripanozomiaze humana: estudos sobre a morfolojia e o ciclo evolutivo do Schizotrypanum cruzi n. gen., n. sp., ajente etiolojico de nova entidade morbida do homem," Memórias do Instituto Oswaldo Cruz, vol. 1, no. 2, pp. 159-218, 1909.

[2] J. A. Pérez-Molina, F. Norman, and R. López-Vélez, "Chagas disease in non-endemic countries: epidemiology, clinical presentation and treatment," Current Infectious Disease Reports, vol. 14, no. 3, pp. 263-274, 2012.

[3] J. A. Pérez-Molina, A. M. Perez, F. F. Norman, B. MongeMaillo, and R. López-Vélez, "Old and new challenges in Chagas disease," The Lancet Infectious Diseases, vol. 15, no. 11, pp. 1347-1356, 2015.

[4] A. F. Nardy, C. G. Freire-de-Lima, A. R. Pérez, and A. Morrot, "Role of Trypanosoma cruzi trans-sialidase on the escape from host immune surveillance," Frontiers in Microbiology, vol. 7, p. $348,2016$.
[5] C. C. Kuehn, L. G. R. Oliveira, M. A. Miranda, and J. C. Prado, "Distinctive histopathology and modulation of cytokine production during oral and intraperitoneal Trypanosoma cruzi Y strain infection," Parasitology, vol. 141, no. 7, pp. 904-913, 2014.

[6] A. A. Rodrigues, A. F. O. Notário, T. L. Teixeira et al., "A high throughput analysis of cytokines and chemokines expression during the course of Trypanosoma cruzi experimental oral infection," Acta Tropica, vol. 157, pp. 42-53, 2016.

[7] N. A. Guerrero, M. Camacho, L. Vila et al., "Cyclooxygenase-2 and prostaglandin $\mathrm{E}_{2}$ signaling through prostaglandin receptor EP-2 favor the development of myocarditis during acute Trypanosoma cruzi infection," PLoS Neglected Tropical Diseases, vol. 9, no. 8, article e0004025, 2015.

[8] F. R. Gutierrez, T. W. Mineo, W. R. Pavanelli, P. M. Guedes, and J. S. Silva, "The effects of nitric oxide on the immune system during Trypanosoma cruzi infection," Memórias do Instituto Oswaldo Cruz, vol. 104, pp. 236-245, 2009.

[9] R. Pérez-Fuentes, J.-F. Guégan, C. Barnabé et al., "Severity of chronic Chagas disease is associated with cytokine/antioxidant imbalance in chronically infected individuals," International Journal for Parasitology, vol. 33, no. 3, pp. 293-299, 2003.

[10] G. Metz, Y. Carlier, and B. Vray, "Trypanosoma cruzi upregulates nitric oxide release by IFN- $\gamma$-preactivated macrophages, limiting cell infection independently of the respiratory burst," Parasite Immunology, vol. 15, no. 12, pp. 693-699, 1993.

[11] R. A. Kelly, J. L. Balligand, and T. W. Smith, "Nitric oxide and cardiac function," Circulation Research, vol. 79, no. 3, pp. 363380, 1996.

[12] G. N. Vespa, F. Q. Cunha, and J. S. Silva, "Nitric oxide is involved in control of Trypanosoma cruzi-induced parasitemia and directly kills the parasite in vitro," Infection and Immunity, vol. 62, no. 11, pp. 5177-5182, 1994.

[13] R. Sesti-Costa, Z. A. Carneiro, M. C. Silva et al., "Ruthenium complex with benznidazole and nitric oxide as a new candidate for the treatment of chagas disease," PLoS Neglected Tropical Diseases, vol. 8, no. 10, article e3207, 2014.

[14] C. M. Carvalho, J. C. Silverio, A. A. da Silva et al., "Inducible nitric oxide synthase in heart tissue and nitric oxide in serum of Trypanosoma cruzi-infected rhesus monkeys: association with heart injury," PLoS Neglected Tropical Diseases, vol. 6, no. 5, article e1644, 2012.

[15] F. S. Machado, G. A. Martins, J. C. Aliberti, F. L. Mestriner, F. Q. Cunha, and J. S. Silva, "Trypanosoma cruzi-infected cardiomyocytes produce chemokines and cytokines that trigger potent nitric oxide-dependent trypanocidal activity," Circulation, vol. 102, no. 24, pp. 3003-3008, 2000.

[16] J. S. Silva, F. S. Machado, and G. A. Martins, "The role of nitric oxide in the pathogenesis of Chagas disease," Frontiers in Bioscience, vol. 8, no. 6, pp. s314-s325, 2003.

[17] M. Chandra, H. B. Tanowitz, S. B. Petkova et al., "Significance of inducible nitric oxide synthase in acute myocarditis caused by Trypanosoma cruzi (Tulahuen strain)," International Journal for Parasitology, vol. 32, no. 7, pp. 897-905, 2002.

[18] B. Chandrasekar, P. C. Melby, D. A. Troyer, J. T. Colston, and G. L. Freeman, "Temporal expression of pro-inflammatory cytokines and inducible nitric oxide synthase in experimental acute Chagasic cardiomyopathy," The American Journal of Pathology, vol. 152, no. 4, pp. 925-934, 1998. 
[19] M. T. Ziolo, M. J. Kohr, and H. Wang, "Nitric oxide signaling and the regulation of myocardial function," Journal of Molecular and Cellular Cardiology, vol. 45, no. 5, pp. 625-632, 2008.

[20] H. B. Tanowitz, S. Mukherjee, D. Zhao et al., "Role of NO synthase in the development of Trypanosoma cruzi-induced cardiomyopathy in mice," The American Journal of Tropical Medicine and Hygiene, vol. 80, no. 5, pp. 782-787, 2009.

[21] K. L. Cummings and R. L. Tarleton, "Inducible nitric oxide synthase is not essential for control of Trypanosoma cruzi infection in mice," Infection and Immunity, vol. 72, no. 7, pp. 4081-4089, 2004.

[22] F. S. Machado, S. Mukherjee, L. M. Weiss, H. B. Tanowitz, and A. W. Ashton, "Bioactive lipids in Trypanosoma cruzi infection," Advances in Parasitology, vol. 76, pp. 1-31, 2011.

[23] A. D. Malvezi, C. Panis, R. V. da Silva et al., "Inhibition of cyclooxygenase- 1 and cyclooxygenase- 2 impairs Trypanosoma cruzi entry in cardiac cell and promotes differential modulation of inflammatory response," Antimicrobial Agents and Chemotherapy, vol. 58, no. 10, pp. 6157-6164, 2014.

[24] J. J. Wirth and F. Kierszenbaum, "Stimulatory effects of leukotriene $\mathrm{B}_{4}$ on macrophage association with and intracellular destruction of Trypanosoma cruzi," Journal of Immunology, vol. 134, no. 3, pp. 1989-1993, 1985.

[25] A. Talvani, F. S. Machado, G. C. Santana et al., "Leukotriene $B_{4}$ induces nitric oxide synthesis in Trypanosoma cruzi-infected murine macrophages and mediates resistance to infection," Infection and Immunity, vol. 70, no. 8, pp. 4247-4253, 2002.

[26] C. Panis, T. L. Mazzuco, C. Z. F. Costa et al., "Trypanosoma cruzi: effect of the absence of 5-lipoxygenase (5-LO)-derived leukotrienes on levels of cytokines, nitric oxide and iNOS expression in cardiac tissue in the acute phase of infection in mice," Experimental Parasitology, vol. 127, no. 1, pp. 58-65, 2011.

[27] C. L. Borges, R. Cecchini, V. L. H. Tatakihara et al., "5-Lipoxygenase plays a role in the control of parasite burden and contributes to oxidative damage of erythrocytes in murine Chagas' disease," Immunology Letters, vol. 123, no. 1, pp. 38-45, 2009.

[28] W. R. Pavanelli, F. R. S. Gutierrez, F. S. Mariano et al., "5Lipoxygenase is a key determinant of acute myocardial inflammation and mortality during Trypanosoma cruzi infection," Microbes and Infection, vol. 12, no. 8-9, pp. 587-597, 2010.

[29] X. S. Chen, J. R. Shelter, E. N. Johnson, and C. D. Funk, "Role of leukotrienes revealed by targeted disruption of the 5lipoxygenase gene," Nature, vol. 372, no. 6502, pp. 179-182, 1994.

[30] S. LHP and V. Nussenzweig, "Sôbre uma cepa de Trypanosoma cruzi altamente virulenta para o camundongo branco," Folia Clinica et Biologica, vol. 20, pp. 191-208, 1953.

[31] B. Zingales, S. G. Andrade, M. R. S. Briones et al., "A new consensus for Trypanosoma cruzi intraspecific nomenclature: second revision meeting recommends TcI to TcVI," Memórias do Instituto Oswaldo Cruz, vol. 104, no. 7, pp. 1051-1054, 2009.

[32] T. P. Misko, W. M. Moore, T. P. Kasten et al., "Selective inhibition of the inducible nitric oxide synthase by aminoguanidine," European Journal of Pharmacology, vol. 233, no. 1, pp. 119-125, 1993.

[33] M. F. Mahmoud, S. Zakaria, and A. Fahmy, "Can chronic nitric oxide inhibition improve liver and renal dysfunction in bile duct ligated rats?," Advances in Pharmacological Sciences, vol. 2015, Article ID 298792, 7 pages, 2015.

[34] G. A. Martins, L. Q. Vieira, F. Q. Cunha, and J. S. Silva, "Gamma interferon modulates CD95 (Fas) and CD95 ligand (Fas-L) expression and nitric oxide-induced apoptosis during the acute phase of Trypanosoma cruzi infection: a possible role in immune response control," Infection and Immunity, vol. 67, no. 8, pp. 3864-3871, 1999.

[35] C. Chatziantoniou, J. J. Boffa, R. Ardaillou, and J. C. Dussaule, "Nitric oxide inhibition induces early activation of type I collagen gene in renal resistance vessels and glomeruli in transgenic mice. Role of endothelin," The Journal of Clinical Investigation, vol. 101, no. 12, pp. 2780-2789, 1998.

[36] A. Mehanna, D. C. Vitorino, C. Panis, E. E. A. Blanco, P. Pinge-Filho, and M. C. Martins-Pinge, "Cardiovascular and pulmonary effects of NOS inhibition in endotoxemic conscious rats subjected to swimming training," Life Sciences, vol. 81, no. 16, pp. 1301-1308, 2007.

[37] Z. Brener, "Therapeutic activity and criterion of cure on mice experimentally infected with Trypanosoma cruzi," Revista do Instituto de Medicina Tropical de Sao Paulo, vol. 4, pp. 389396, 1962.

[38] B. Gonzalez Flecha, S. Llesuy, and A. Boveris, "Hydroperoxideinitiated chemiluminescence: an assay for oxidative stress in biopsies of heart, liver, and muscle," Free Radical Biology \& Medicine, vol. 10, no. 2, pp. 93-100, 1991.

[39] E. Roggero, A. Perez, M. Tamae-Kakazu et al., "Differential susceptibility to acute Trypanosoma cruzi infection in BALB/c and C57BL/6 mice is not associated with a distinct parasite load but cytokine abnormalities," Clinical and Experimental Immunology, vol. 128, no. 3, pp. 421-428, 2002.

[40] C. Panis, A. C. S. A. Herrera, V. J. Victorino et al., "Oxidative stress and hematological profiles of advanced breast cancer patients subjected to paclitaxel or doxorubicin chemotherapy," Breast Cancer Research and Treatment, vol. 133, no. 1, pp. 8997, 2012.

[41] M. Repetto, C. Reides, M. L. Gomez Carretero, M. Costa, G. Griemberg, and S. Llesuy, "Oxidative stress in blood of HIV infected patients," Clinica Chimica Acta, vol. 255, no. 2, pp. 107-117, 1996.

[42] A. D. Malvezi, R. Cecchini, F. de Souza, C. E. Tadokoro, L. V. Rizzo, and P. Pinge-Filho, "Involvement of nitric oxide (NO) and TNF- $\alpha$ in the oxidative stress associated with anemia in experimental Trypanosoma cruzi infection," FEMS Immunology \& Medical Microbiology, vol. 41, no. 1, pp. 69-77, 2004.

[43] M. A. Munoz-Fernandez, M. A. Fernandez, and M. Fresno, "Synergism between tumor necrosis factor-alpha and interferon-gamma on macrophage activation for the killing of intracellular Trypanosoma cruzi through a nitric oxidedependent mechanism," European Journal of Immunology, vol. 22, no. 2, pp. 301-307, 1992.

[44] C. H. Serezani, J. H. Perrela, M. Russo, M. Peters-Golden, and S. Jancar, "Leukotrienes are essential for the control of Leishmania amazonensis infection and contribute to strain variation in susceptibility," Journal of Immunology, vol. 177, no. 5, pp. 3201-3208, 2006.

[45] G. Larfars, F. Lantoine, M. A. Devynck, J. Palmblad, and H. Gyllenhammar, "Activation of nitric oxide release and oxidative metabolism by leukotrienes $\mathrm{B}_{4}, \mathrm{C}_{4}$, and $\mathrm{D}_{4}$ in human polymorphonuclear leukocytes," Blood, vol. 93, no. 4, pp. 1399-1405, 1999. 
[46] A. M. C. Canavaci, C. A. Sorgi, V. P. Martins et al., "The acute phase of Trypanosoma cruzi infection is attenuated in 5lipoxygenase-deficient mice," Mediators of Inflammation, vol. 2014, Article ID 893634, 17 pages, 2014.

[47] L. E. Fichera, M. C. Albareda, S. A. Laucella, and M. Postan, "Intracellular growth of Trypanosoma cruzi in cardiac myocytes is inhibited by cytokine-induced nitric oxide release," Infection and Immunity, vol. 72, no. 1, pp. 359-363, 2004.

[48] M. Peters-Golden and W. R. Henderson Jr., "Leukotrienes," The New England Journal of Medicine, vol. 357, no. 18, pp. 1841-1854, 2007.

[49] C. A. Feghali and T. M. Wright, "Cytokines in acute and chronic inflammation," Frontiers in Bioscience: A Journal and Virtual Library, vol. 2, pp. d12-d26, 1997.

[50] E. Martin, C. Nathan, and Q. W. Xie, "Role of interferon regulatory factor 1 in induction of nitric oxide synthase," The Journal of Experimental Medicine, vol. 180, no. 3, pp. 977984, 1994.

[51] S. Jozefowski, R. Biedron, M. Bobek, and J. Marcinkiewicz, "Leukotrienes modulate cytokine release from dendritic cells," Immunology, vol. 116, no. 4, pp. 418-428, 2005.

[52] D. DiMeo, J. Tian, J. Zhang, S. Narushima, and D. J. Berg, "Increased interleukin-10 production and Th2 skewing in the absence of 5-lipoxygenase," Immunology, vol. 123, no. 2, pp. 250-262, 2008.

[53] R. S. Deeb, H. Shen, C. Gamss et al., "Inducible nitric oxide synthase mediates prostaglandin $\mathrm{H}_{2}$ synthase nitration and suppresses eicosanoid production," The American Journal of Pathology, vol. 168, no. 1, pp. 349-362, 2006.

[54] R. K. Upmacis, R. S. Deeb, and D. P. Hajjar, "Regulation of prostaglandin $\mathrm{H}_{2}$ synthase activity by nitrogen oxides," Biochemistry, vol. 38, no. 38, pp. 12505-12513, 1999.

[55] R. L. Cardoni and M. I. Antunez, "Circulating levels of cyclooxygenase metabolites in experimental Trypanosoma cruzi infections," Mediators of Inflammation, vol. 13, no. 4, 240 pages, 2004.

[56] V. L. Hideko Tatakihara, R. Cecchini, C. L. Borges et al., "Effects of cyclooxygenase inhibitors on parasite burden, anemia and oxidative stress in murine Trypanosoma cruzi infection," FEMS Immunology and Medical Microbiology, vol. 52, no. 1, pp. 47-58, 2008.

[57] J. Mauel, A. Ransijn, S. B. Corradin, and Y. Buchmuller-Rouiller, "Effect of $\mathrm{PGE}_{2}$ and of agents that raise cAMP levels on macrophage activation induced by IFN- $\gamma$ and TNF- $\alpha$," Journal of Leukocyte Biology, vol. 58, no. 2, pp. 217-224, 1995.

[58] K. Schulze-Osthoff, A. C. Bakker, B. Vanhaesebroeck, R. Beyaert, W. A. Jacob, and W. Fiers, "Cytotoxic activity of tumor necrosis factor is mediated by early damage of mitochondrial functions. Evidence for the involvement of mitochondrial radical generation," The Journal of Biological Chemistry, vol. 267, no. 8, pp. 5317-5323, 1992.

[59] C. Hartel, J. von Puttkamer, F. Gallner, T. Strunk, and C. Schultz, "Dose-dependent immunomodulatory effects of acetylsalicylic acid and indomethacin in human whole blood: potential role of cyclooxygenase-2 inhibition," Scandinavian Journal of Immunology, vol. 60, no. 4, pp. 412-420, 2004. 


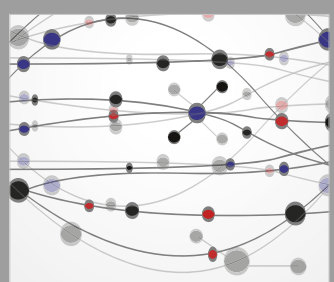

The Scientific World Journal
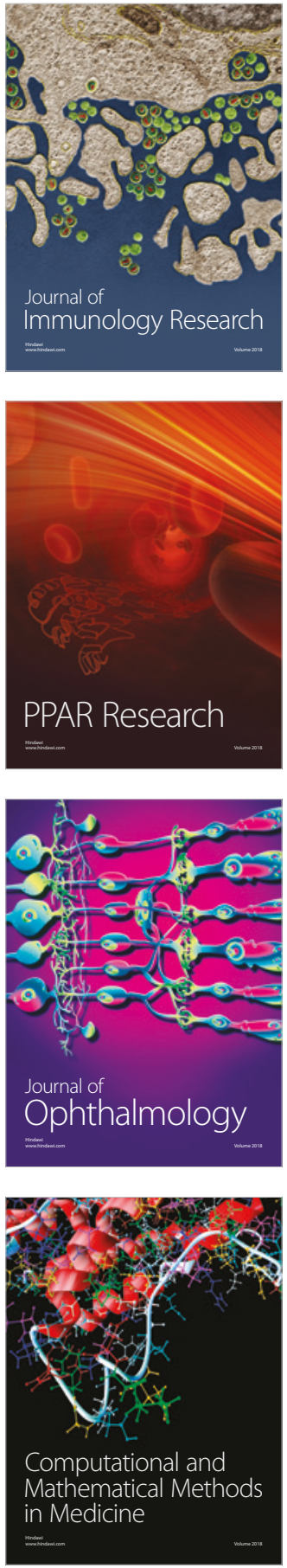

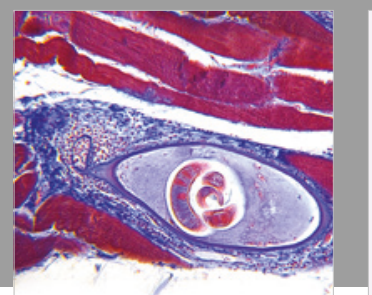

Gastroenterology Research and Practice

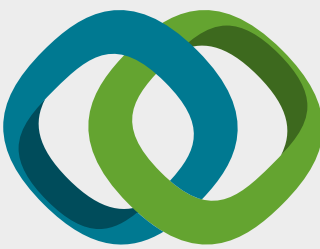

\section{Hindawi}

Submit your manuscripts at

www.hindawi.com
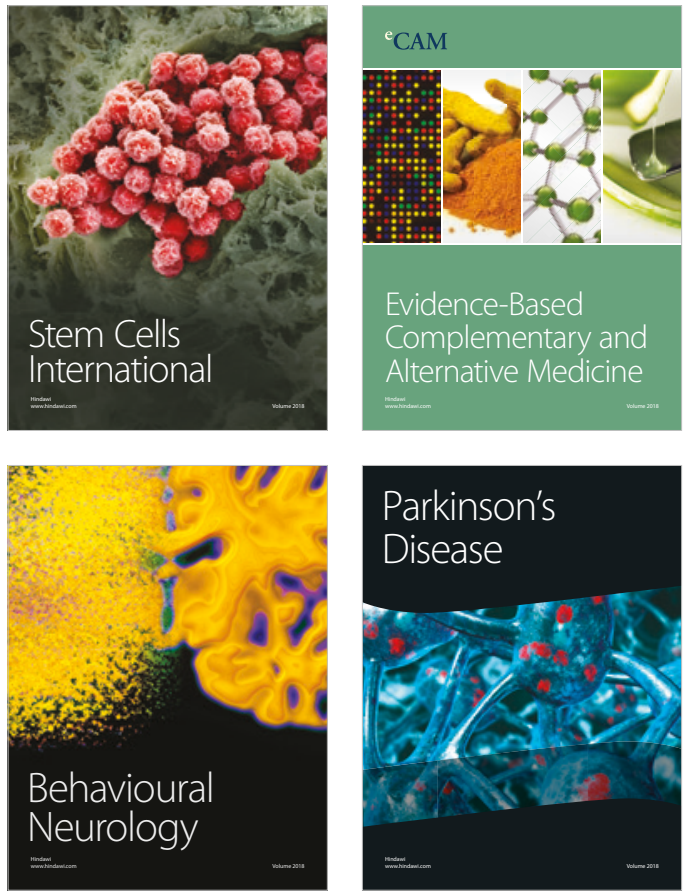

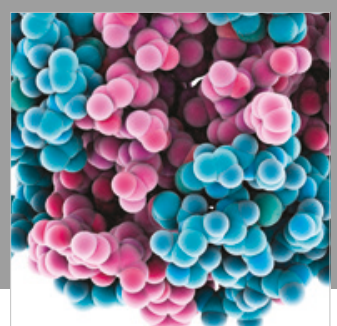

ournal of

Diabetes Research

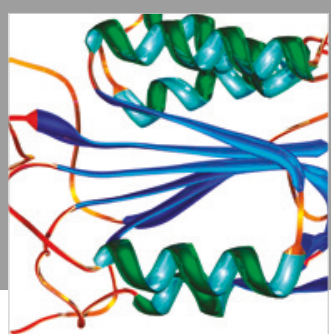

Disease Markers
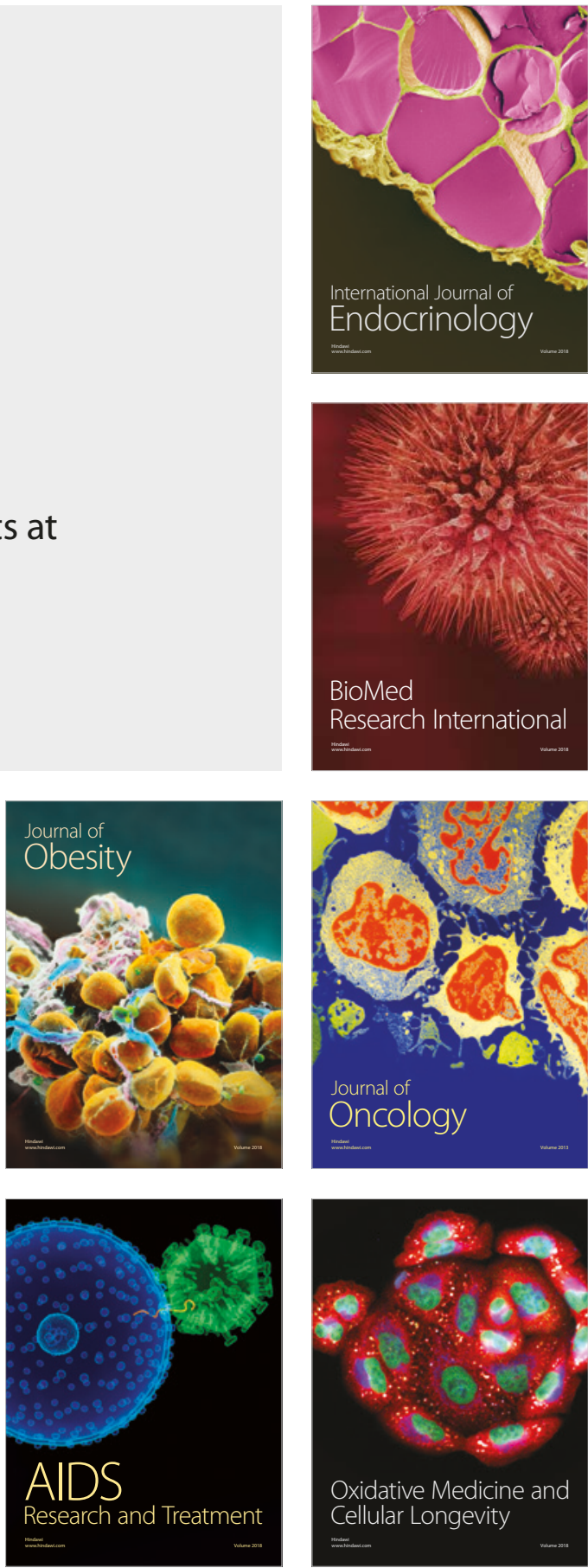